\title{
THIS HATE
}

It is like a fitting-room only with eight or nine mirrors instead of three-

only, no door.

But you see: no ceiling. They never do.

I love them, my mother, my daughter. Both. I do, and I can write it out and seal it

but it hurts, the mirrors closing in.

Now: the stamp.

I have to do this very carefully,

looking up; I feel, you see, the fontanel's gentle

beat at closing.

Carefully now-the shine is blinding-

I have to jump and drop it out, over.

Now I need a skin.

Or maybe this fogging up

transparency is it. Is it?

It feels like yours, more or less;

only for the face.

\section{A.M. IN NEW YORK}

I have been standing at the edge of this green field all night.

My hand is sticky with sugar.

The village winks; it thinks it is the muscle of the world. The heart.

The mouth.

The horse is standing across the field, near the fence.

He doesn't come any closer, even in the dark, or run away.

Blood memory:

fixed on vacancy:

coming back and back for a sign

the flat of his coat

the shut out of his eye. 